\title{
THE RUTGERS COOPERATIVE EXTENSION BULLETIN BOARD (RCEBBS)
}

\section{BY BRUCE BARBOUR}

\author{
Mr. Barbour is County Agricultural Agent, \\ Rutgers Cooperative Extension of Sussex County
}

Computer Bulletin Boards are the combination of software and hardware which permit callers from remote sites to communicate and share information by posting messages, exchanging files and communicate with each other in real time using interactive messaging. With the advent of the personal computer in the early eighties this capability spawned a boom in computer to computer communication, facilitated by the appearance of inexpensive yet sophisticated bulletin board software and modems capable of ever-increasing rates of information transfer.

While computer bulletin boards are today appearing more and more frequently in the corporate and academic worlds there are literally thousands of hobby boards throughout the nation. The software in use on these hobby boards is sometimes more versatile and user-friendly than that used in commercial applications by virtue of the heavy use that the "hobby" systems attract which translates into more feedback to the authors and thus more frequent refinement and revision of their software.

The computer bulletin board system (BBS) has three abilities which should make it of interest to those of us in Cooperative Extensiontime-utility, labor efficiency, and accountability.

First consider time-utility. It collects and retains information from callers which it holds in ready access, providing much the same service as a telephone answering machine. Unlike the answering machine, however, the BBS is not limited as to the amount and complexity of information it can store, and it can handle graphical as well as text-based information. The BBS message system is the perfect tool for busy individuals who need to communicate but are not always accessible by phone. It eliminates "telephone tag". A busy farmer can leave a question on an Extension BBS at $11 \mathrm{pm}$ and read the reply at noon the next day while the Extension Specialist he is communicating with is off to lunch. 
Second, the BBS is labor efficient. It operates 24 hours a day, seven days a week, making its information available to callers even when no operator is present. It collects the day's messages and lets Extension professionals respond to all their mail in one or more sessions which can be scheduled for convenience. It is also remotely accessible with a portable computer, obviating wasteful travel and even permitting work from home. Information collected and stored on the BBS system accumulates and builds an easily accessible library which is just as accessible to new callers to the system as to the old hands who took part in the original dialogues. This is true of files and bulletins as well as correspondence in the message base provided the operator does not deem particular information dated and delete it when its purpose has been served.

The third virtue of a computer bulletin board is accountability. Any good system will maintain a log of all caller activity from which reports can be generated showing in great detail exactly how much and what sort of activity is taking place during the operational hours of the BBS. This information can be of great help in assessing relevance and popularity of features on the board. It also helps justify expense related to the system operation. The system operator (SYSOP) can soon get to know who the regular users are and which ones may be having difficulty utilizing the system. The log serves the SYSOP as a diagnostic tool when a user is having difficulty but cannot adequately explain where the problem is. Of course the $\log$ and the reports which can be generated from it are invaluable for reporting requirements.

\section{The Computer Bulletin Board at Rutgers Cooperative Extension}

Rutgers Cooperative Extension has operated a public access computer bulletin board system since October 1987 . The system features information and discussions relating to agriculture and the environment. Specifically, it contains text files of most Rutgers Cooperative Extension publications, bulletins and newsletters from Extension Specialists, weather, agricultural news, and terminal market price information for produce and ornamentals as well as herbs, nuts, and exotic crops. The Rutgers Cooperative Extension Bulletin Board System (RCEBBS) also is affiliated with the New Jersey State Data Center and the Bureau of the Census, through which it obtains the latest releases of agriculture census, economic census and general census data. RCEBBS also features a unique, searchable, database of regulations and legislation 
affecting agriculture; the database is maintained by Rutgers Cooperative Extension in cooperation with several other state agencies.

RCEBBS is participating in the national Extension CD-ROM project and added a double CD-ROM drive to the system in early 1990. The National Extension Sampler, as the disk finally came to be known, increased the volume of documents available on RCEBBS by approximately ten-fold. What follows is a summary of the contents from the disk itself:

The disc contains over 75 major collections and handbooks from the National Agricultural Library, USDA, and Extension Services across the nation. In addition, there are numerous smaller documents available on the disc, ranging from such topics as water quality to health and nutrition to community and economic development.

Listed below are the collections names and sizes of the documents contained on this disk.

approx.

pages documents

Alabama Pecan Production Handbook .......... . 314

California Teletip Factsheet Collection . . . . . . . . 318

Cornell Home Fruit Planting Guide . . . . . . . . . . 75

Cornell Pesticides and Groundwater Guide . . . . . . 18

Dear John Horticulture Newspaper Column . . . . . . . 504

Delaware Police Management Guidelines . . . . . . . 39

Electronic Mail Userid Lists . . . . . . . . . . . . . . . . 29

Florida Clothing Collection . . . . . . . . . . . . 68

Florida Factsheet Collection ................ 743

Florida Manual of Minor Vegetables . . . . . . . . . . . . 148

FmHA Instruction Booklet. . . . . . . . . . . . . . 606

Indiana Volunteer Coordinator System . . . . . . . . . 35

Iowa Feeling Good Collection . . . . . . . . . . . . 75

Kansas Nutrition Collection ................ 179

Louisiana Extension Teletips . . . . . . . . . . . . . 552

Maryland Retirement Planning Guide ..........66 61

Michigan Food Preservation Collection .......... 244

Michigan Home Horticulture Collection . . . . . . . . 715

Michigan Home Maintenance Collection . . . . . . . . 236

Minnesota Cold Climate Collection ............ 81

Minnesota Pollution Control Guide ............ 58

Minnesota Social Sciences in Forestry . . . . . . . 2530 


\begin{tabular}{|c|c|}
\hline $\begin{array}{c}\text { approx. } \\
\text { pages }\end{array}$ & documents \\
\hline Misc. documents not listed in a collection. & 221 \\
\hline Montana Guide Sheet Collection ....... & 159 \\
\hline NAL Dairy Reproductive Management ........ & 26 \\
\hline NAL Extension Goat Handbook ................. 394 & 69 \\
\hline NAL National Corn Handbook . ............ & 31 \\
\hline NAL National Corn Production Handbook .. & 21 \\
\hline NAL Pork Industry Handbook $\ldots \ldots \ldots \ldots \ldots$ & 101 \\
\hline NAL Soil Taxonomy . . . . . . . . . . . . . . . 926 & 72 \\
\hline NAL Status of Warmwater Fish Farming . . . . . . . 366 & 32 \\
\hline NAL Wood Handbook . . . . . . . . . . . . . . . 231 & 21 \\
\hline NAL Woodland Workbook. . . . . . . . . . . . 198 & 20 \\
\hline National Dairy Science Database. . . . . . . . . . . 2022 & 275 \\
\hline NC Region Educational Materials Project . ....... 1631 & 93 \\
\hline Nebraska Alternative Agriculture . . . . . . . . . 1286 & 171 \\
\hline Nebraska Great Plains Songbirds. . . . . . . . . . . 37 & 26 \\
\hline Nebraska Nebguides Collection ............... 174 & 37 \\
\hline Nebraska Wildlife Damage Handbook . . . . . . . . . 806 & 112 \\
\hline New Mexico Tree Disease Collection . .......... 37 & 4 \\
\hline North Carolina Working with Our Publics ........ 566 & 38 \\
\hline NRAES Assessing Used Farm Equipment. . . . . . . 25 & 2 \\
\hline NRAES Bramble Production Guide . ........... 173 & 15 \\
\hline NRAES Extinguishing Silo Fires $\ldots \ldots \ldots \ldots \ldots$ & 1 \\
\hline NRAES Livestock Building Fire Control . . . . . . . 21 & 2 \\
\hline Ohio Agronomy Guide $\ldots \ldots \ldots \ldots \ldots \ldots \ldots \ldots \ldots$ & 4 \\
\hline Ohio Horticultural Notes $\ldots \ldots \ldots \ldots \ldots \ldots$ & 23 \\
\hline Oregon Nutrition Bibliography . . . . . . . . . . . . 1499 & 16 \\
\hline Oregon Vegetable Variety Recommendations . . . . . . 713 & 51 \\
\hline PENNPAGE's - Factsheets from Pennsylvania . . . . . 9951 & 3581 \\
\hline Purdue Pork Production Handbook . . . . . . . . . & 14 \\
\hline South Carolina Extension Publications . . . . . . . . . 1605 & 1012 \\
\hline Texas Adult Day Care Center Collection ......... & 34 \\
\hline Texas Alzheimer Family Support $\ldots \ldots \ldots \ldots \ldots$ & 5 \\
\hline Texas Aquaculture Collection.$\ldots \ldots \ldots \ldots \ldots$ & 7 \\
\hline US Consumer Resource Handbook............. 176 & 28 \\
\hline USDA 1986 Fact Book of Agriculture . . . . . . . . . 133 & 12 \\
\hline JSDA 1989 Accomplishment Reports (NARS) . . . . 2984 & 1777 \\
\hline DA 1989 Factbook . . . . . . . . . . . . . 153 & 18 \\
\hline
\end{tabular}




\begin{tabular}{|c|c|}
\hline $\begin{array}{c}\text { approx. } \\
\text { pages }\end{array}$ & documents \\
\hline USDA 1989 Year Book of Agriculture . . . . . . . . . 359 & 67 \\
\hline USDA Complete Guide to Home Canning . ..... & 10 \\
\hline USDA FY88-91 Plans of Work (POW) . . . . . . . . . 4546 & 2488 \\
\hline USDA Technology Transfer Publication . . . . . . . . 40 & 2 \\
\hline Utah Family Collection $\ldots \ldots \ldots \ldots \ldots \ldots \ldots \ldots 66$ & 9 \\
\hline Virginia Adolescence Collection . . . . . . . . . . . 24 & 12 \\
\hline Virginia Extension Fact Sheets . . . . . . . . . . . 824 & 703 \\
\hline Virginia Food Preservation Handbook ........... 230 & 25 \\
\hline Virginia Horticultural Factsheets . . . . . . . . . . 1446 & 1092 \\
\hline Virginia Master Gardener Handbook . ........... 672 & 517 \\
\hline Virginia Pesticide Safety Collection $\ldots \ldots \ldots \ldots \ldots 150$ & 83 \\
\hline Washington State Transitions for Growth ........ 303 & 30 \\
\hline Washington State Youth At Risk Series $\ldots \ldots \ldots \ldots$ & 48 \\
\hline Western Farm Management Collection . ......... 1131 & 85 \\
\hline Wisconsin Urban Phytonarian Handbook . . . . . . . . . . 789 & 163 \\
\hline Virginia Work Simplification Series . . . . . . . . & 4 \\
\hline
\end{tabular}

Interest Area Titles and Sizes

approx.

pages documents

Crops and Horticulture . . . . . . . . . . . . 11,121

4136

Consumerism and Family . . . . . . . . . . . . 11,090

3539

Resources and References ................... . 285

Natural Resources and Wildlife . . . . . . . . . . . 4532

Livestock . . . . . . . . . . . . . . . . . . . . 6928

Pests and Diseases....................... 1473

1496

Staff Development and Administration . . . . . . . . 299

4-H and Youth Development............... 1714

Community Economic Development . . . . . . . . . 1361

Farm Management and Ag. Engineering . . . . . . 1507 
In a similar manner RCEBBS made available to its users a CD-ROM disk of "The 1987 Census of Agriculture from the Bureau of the Census, which contained data for all states and all of their counties nationwide. Users can quickly view tables summarizing the size and character of agriculture in any county in the nation in greater detail than found in most hard copy versions of this census.

\section{Structure and Features}

The Rutgers Cooperative Extension Bulletin Board Service (RCEBBS) is a computer bulletin board accessible to all modem equipped personal computers via telephone.

The Board can support four basic communication forms:

1) Messages

2) Bulletins

3) File Directories

4) Conferences

MESSAGES can be left by all callers who register with the Board. They can be addressed to other registered callers as private or public messages [ALL] or to the board operator [SYSOP]. (Registration is accomplished by simply answering a brief questionnaire the first time you call in and then answering a second, more detailed questionnaire accessed by selecting [S] "Script Questionnaire" at the main menu.) The maximum length of a message is limited to 99 lines.

BULLETINS are static messages available for viewing by all users. They can be of any length and the Board can feature up to 99 at any given time. For instance, many Extension newsletters are posted as bulletins, as is the daily Farmer's Forecast and the System rules and subscription information.

FILE DIREC'TORIES can hold files which are either text, executable code, or both. The file directories serve as a library of material which can be downloaded by users for use or reading at a later date. Users can also contribute to the store of information available on the board by uploading files to the board. RCEBBS can maintain up to 99 file directories. Directories are a feature used to arrange files by subject matter content. Within each directory individual file names are listed with a one line description of what is in the file.

RCEBBS offers two helpful features for finding information in the file directories, "Zippy Scan" and "Locate a File". "Zippy Scan" searches the file directories for a given word or string of text, searching 
both the file names and the descriptions that follow each file. "Locate a File" searches only the file names and should be entered following the DOS convention of a file name and extension. Wild card characters are acceptable when using "Locate a File".

CONFERENCES feature all three of the above features. Conferences usually are used to serve as forums for exchanges in a particular subject matter area. For instance we could have a "Fruit Production" conference or a "Field Crops" conference, or a "Gardening" conference. Access to conferences can be controlled by the system operator (SYSOP). Therefore both public and private conferences can be established by prior arrangement with the SYSOP. The dialogue accumulated as messages over a period of time in a conference could potentially become a valuable database. RCEBBS can search the headers of conference messages for specific words or phrases (strings), making searching of past discussions fairly easy. RCEBBS can maintain up to nine conferences at one time.

At this time RCEBBS has only one conference which is concerned with marketing and open only to Cooperative Extension professionals.

\section{Getting On-Line}

The toll free number of the RGEBBS is $800 / 722-0335$; however, this is only accessible in New Jersey to paying subscribers. The board will answer callers whose communications software is set at either "N-8-1" or "E-7-1" but file transfers can only be done when a caller is using the "N-8-1" format. "N" stands for No Parity, "8" stands for 8 Bit Word Length and " 1 " stands for 1 Stop Bit. The manual which comes with the caller's particular communications software will tell them how to adjust these parameters. RCEBBS also has a second node which operates with a standard phone line with the number 201/383-8041.

On the initial call, callers will receive 6 minutes of access time and will be asked if they want to register. When they indicate that they want to register they are asked for some basic information (Name, Phone, Town). Completion of this initial questionnaire is necessary for subsequent subscription to the system. It also automatically gives them 30 minutes per day of limited access on the standard phone number (nontoll free). However, until a $\$ 15$ per year subscription fee is submitted, access to system features is quite limited.

At all times the caller is presented with menus or instructions describing the available options. For more on the menus, file directories and other system features see Appendix A. 


\section{Equipment and Software}

RCEBBS runs on an Everex System 3000 which has a 80386 processor running the MS DOS 3.3 operating system and 170 megabytes of hard disk storage. The bulletin board software is PCBoard ver. 14.5 which is operated under the Desquiew multi-tasking environment with Quarterdeck's Expanded Memory Manager for the 386. The machine has five megabytes of memory and two incoming lines to one internal and one external modem each of which is capable of transmissions at $300,1200,2400$ and 9600 baud. The bulletin board is also supported by a Mountain tape backup, Hewitt Packard Scanner, and Calera Truescan Page recognition package all of which insure the integrity of the system and aid in the input and formatting of text for use on the system.

Currently one node has a statewide WATS (toll free) line and the other has a standard phone line.

File transfer protocols supported include ASCII, Xmodem, Ymodem, and $\mathrm{Zmodem}$.

\section{Use and Evaluation}

As of January 1993 the system has almost 2,700 users and has received 55,000 calls since its inception in October 1987. About 300 users pay the $\$ 15$ annual subscription fee which gives them full access to all the features on RCEBBS and one hour per day on the toll free line. Two percent of the callers are engaged full or part time in agriculture, a statistic which echoes the overall ratio of farmer to non-farm population in New Jersey. Another two percent of the callers report being actively engaged in environmental or educational posts or organizations. The average age of our callers is just under 30 years. The majority are male. Most call the system once a week.

Our survey of users' favorite features on the system revealed an almost even split of opinion favoring the bulletins, fact sheets, message base, and other files on the board. In the same survey $43 \%$ of those responding said that the RCEBBS had saved them either time or money, some putting a value of up to $\$ 500$ on the information they had received from the board. The overwhelming majority of comments from users of the system are positive. Most state that the board is well organized, easy to use, and contains valuable information. Many mentioned that this sort of service has been long overdue from government agencies and the university. Many also mention that the toll free line allows them to make much greater use of the system and derive more benefit from it. This 
may be connected to the time needed to explore and learn what is on the board. One can imagine how little use libraries would get if visitors were charged by the minute while inside.

In the past year RCEBBS received 6,272 calls and 921 downloads were recorded on the system. These were files either of Extension Fact Sheets, Bulletins, or files containing executable programs for MS DOS computers collected from the Experiment Stations around the country or uploaded to the system by our users. System reports contain the name of each file transferred and the number of times it was downloaded. 417 different files were accessed in this manner.

In 1992, 1,189 new users signed on to the system. Daily use ranged from 15 to 20 calls per day and the system was in use about $10 \%$ of the time overall.

One of the questions asked of callers as part of the registration process is "What is your occupation or the activity you spend most of your time on?". The responses reveal a broad cross section of society uses the RCEBBS with many students and professionals in the mix.

The evening hours from $5 \mathrm{pm}$ to midnight are the most active on RCEBBS reinforcing the utility of an automated 24 hour a day information delivery system such as this.

\section{Future Plans}

RCEBBS has enjoyed a high level of use and an equally high level of acceptance and praise from its users. The percentage of potential users from the commercial agriculture sector is still not high enough but we believe that it is incumbent on Extension to provide a worthwhile service via computer before expecting farmers to invest the time and money necessary to access that service. The computer bulletin board as an Extension delivery tool was and is still somewhat ahead of its time. We have learned much in operating this public access system, not only about hardware and software, but about people and their behavior when given access to an information resource which allows them not only to read but also to contribute comments and questions.

CD-ROM drives and the databases they read are now becoming easily available and relatively economical. However they are even more economical to users if offered through the medium of an online service such as RCEBBS. We have incorporated two such CD-ROM based resources into our system and continually look for the opportunity to include more. Major considerations are license restraints placed on 
individual CD-ROM databases and the cost of adding additional players to our system.

Text databases searchable by keyword requests were a new addition to RCEBBS in 1989. We have expanded the selection of legislative, regulatory, and marketing information available for searching in this manner as a means of improving the ability of farmers to keep pace with the fast changing world of government regulations and the market. Other possibilities for this format would be pesticide use and safety information, toxicological information relating to pesticides, and an interactive calendar of events which would allow callers to post dates as well as simply to read existing data. The uses for computer bulletin boards are limited principally by one's imagination, not by existing technology or software.

One exception to this has been images, which still were limited by their relatively large size and lack of a uniform software format. However, we are just about to offer a collection of Rutgers Cooperative Extension Fact Sheets and Bulletins as files for download in the encapsulated postscript (EPS) format. These files can be sent directly to a postscript printer using the DOS "Copy" command and will produce a fully formatted document including all fonts, tables and graphics. This is our first venture into using an image-based format for information delivery and it has the limitation of only being immediately accessible to users who have access to a postscript printer. Further evolution of this approach will include offering one or two other image formats which will afford universal access.

An interesting possibility that is now possible with the move to image-based documents is the integration of fax modems and special software to allow the image documents on RCEBBS to also be made available to users who have fax machines. Several companies and institutions are now offering fax document retrieval directly from a touch tone phone. Preliminary discussion of this possibility with Extension audiences has generated strong favorable comment and we will look carefully at this as a future option. Software exists to convert the EPS format files to any of the commonly used fax formats.

Another goal is to make RCEBBS accessible over the Internet. Currently the Internet is not easily accessible to the general public and thus we have not made this link a high priority. But it appears that the Glinton Administration plans to enhance access and capability of this magnificent information highway and thus it would behoove the cre- 
ators of any online information repository to eventually make their resources accessible through it.

It is hoped that New Jersey and Rutgers University will be among the leaders in opening up Internet access to the general public.

\section{APPENDIX A}

What Will You See?

\section{The Main Menu}

To help orient the new user the Main Menu of RCEBBS is reproduced below. The menu is used by selecting the first letter of each menu option and entering it at the command line which follows when online.

In particular new users should note the option "Help Functions" $(H)$. Online help is instantly available for any of the menu functions simply by selecting " $\mathrm{H}$ " and then, in response to the request from the board, specifying which menu option you would like to have explained further.

\begin{tabular}{|c|c|c|c|}
\hline A)bandon Conference & G)oodbye (Hang up) & O)perator Page & TS)Txt Srch Msgs \\
\hline B)ulletin Listings & H)elp Functions & OPEN a DOOR & U)pload a File \\
\hline CHAT between NODEs & I) nitial Welcome & P)age Length Set & UB Upload Batch \\
\hline G)omment to SYSOP & J)oin a Conference & Q)uick Msg Scan & USERS List Users \\
\hline D)ownload a File & K)ill a Message & R)ead Messages & V)iew Settings \\
\hline DB Download Batch & L)ocate Files(name) & REPLY to Msg(s) & W)rite User Info \\
\hline E)nter a Message & M)ode (Graphics) & RM)Re-Read Mem \# & $\mathrm{X})$ pert On/Off \\
\hline F)ile Directories & N)ew Files(date) & S)cript Question & Y)our Per. Mail \\
\hline FLAG for download & NEWS file display & T)rans. Protocol & Z)ippy DIR Scan \\
\hline
\end{tabular}

SELEC'T Conferences for Scanning or Reading

\section{The Bulletin Menu}

As further illustration of the features available on RCEBBS we have reproduced the Bulletin Menu which appears when " $B$ " is selected at the Main Menu. 


\section{$=====$ RUTGERS COOPERATIVE EXTENSION BULLETINS=====}

1. CALENDAR OF EVENTS - Meetings and educational events of interest to Extension Clientele.

2. THE FARMER'S FORECAST - Agriculturally oriented weather.

3. HORTICULTURAL ENGINEERING REPORT- Bill Robert's newsletter.

4. PESTICIDE UPDATE - Information on recent changes in pesticide labeling, regulations and applicator training.

5. RUTGERS FRUIT, VEGETABLE \& FIELD CROP IPM NEWSLETTER

6. 'THE GROWING COLUMN - Claire Liptak, Somerset County Agent

7. BUSINESS MANAGEMENT IN AGRICULTURE (Extension Course)

8. SYSTEM USE STATISTICS- for RCEBBS Nodes $1 \& 2$.

9. FINANCIAL TIP OF THE WEEK- From Rutgers Cooperative Extension Home Economist, Barbara O'Neill.

10. WHAT IS RUTGERS COOPERATIVE EXTENSION-

An introduction to the organization that sponsors this board.

11. NEW YORK TERMINAL MARKET PRICES - Fruit and Vegetables.

12. PHILADELPHIA TERMINAL MARKET PRICES - Fruit and Vegs.

13. INSECT \& DISEASE NEWSLETTER - Dr. Louis Vasvary et al.

14. PA. HAY MARKET PRICES

15. HOUSING AND ENERGY NEWS - Dr. Joseph Ponessa

16. FOOD TECHNOLOGY UPDATE - Dr. Don Schaffner, Ext. Food Science Specialist.

17. SUBSCRIBING TO RCEBBS

18. RCEBBS SYSTEM POLICIES

19. AGSAT PROGRAM SCHEDULE

20. FARM BROADCASTER'S NEWSLETTER

21. WEEKLY WORLD WEATHER AND CROP REPORT

22. OTHER AGRICULTURAL COMPUTER BULLETIN BOARDS

Each Bulletin may be displayed on your screen by entering the appropriate number at the prompt which follows the bulletin menu online.

\section{The File Directory Menu}

Likewise this is the menu which appears in response to entering " $F$ " at the main menu. The contents of each File Directory will be displayed when the appropriate number is selected. 


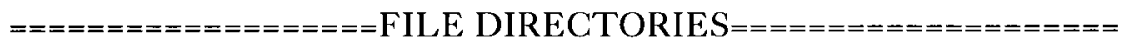

1) The Agricultural Library

2) General Interest

3) Pesticide Information

4) The Fact Sheet Library

5) The Apple Orchard

6) U of Mass. Fact Sheets

7) RCE Bulletins

8) Census Data (via St. Data Ctr.)

9) Recent Uploads

\section{A Typical File Directory}

Note that the files are arranged within each directory in order of date of posting and the file name is followed by the size of the file in kilobytes and the one line description of the file's contents.

On the RCEBBS, files with .ZIP extension are "archived" and need to be unpacked with a utility program, PKZIP. Such files can only be accessed by IBM compatible computers.

All text files are stored on RCEBBS in nonarchived ASCII format and either have no extension or are followed by an extension other than ".ZIP". These files are accessible to virtually all makes and models of computers.

$========$ THE RCEBBS AGRICULTURAL FILE LIBRARY $========$

\begin{tabular}{|c|c|c|c|}
\hline BEEF.ZIP & 41466 & $10-08-87$ & Beef production guide for Lotus (Colorado) \\
\hline BUSMODEL.ZIP & 107629 & $10-08-87$ & Wks files for 325 yr. farm business models \\
\hline CALIB.ZIP & 8089 & $10-08-87$ & $\begin{array}{l}\text { Sprayer Calibration Aid for Multiplan } \\
\text { (Clemson) }\end{array}$ \\
\hline CAPINV.ZIP & 9818 & $10-08-87$ & Wks files on Capital Investment \\
\hline CAR.ZIP & 8834 & $10-08-87$ & Automobile Trade Analysis (Mississippi) \\
\hline COUPONS.ZIP & 40960 & $12-23-87$ & Keep track of your store coupons \\
\hline DFOR.ZIP & 12964 & $10-04-87$ & Dairy Ration Balancer (Mississippi) \\
\hline
\end{tabular}

A master list of all files on RCEBBS is created each day under the name MASTER.ZIP.

A complete set of the online help texts is contained in the files PCBHELP.TXT (ASCII text) and PCBHELP.ZIP (Archived ASCII text). 


\section{The Doors}

The CD-ROMs and text databases on RCEBBS are accessible through a feature called a Door. When in a Door the user is really using an external program that was not originally written as part of the PCBoard software. This gives the system operator great flexibility for expanding features on the board but is virtually transparent to the user. This is the current Door menu:

1) TEXT SEARCH DOOR: Contains the following "textbases":

A) Summary of NJ law and regulations relating to Agriculture

B) NJ Pesticide Control Regulations

NJAC Title 7, Chapter 30, Subchapters 1-10

C) Scientific Literature on Alternative Farming Systems. 6,289 citations ranging from 1916 to 1985 created by the USDA and North Carolina State University. Authors: R.H. Miller, L.D. King, P.G. Sullivan

D) The Urban Phytonarian Handbook - A complete guide to home horticulture from the University of Wisconsin.

E) Alternative Agricultural Opportunities Bibliography

2) NA'TIONAL EXTENSION CD-ROM SAMPLER

12,000 Documents online from around the nation. One of the most extensive information collections available, with full text search.

3) U.S. CENSUS OF AGRICULTURE CD-ROM

\section{APPENDIX B}

\section{Addresses of Software Vendors}

DESQVIEW is a product of QuarterdeckOffice Systems, 150 Pico Boulevard, Santa Monica, CA 90405 .

PCBOARD is a product of Clark Development Company, Inc., P.O. Box 571365, Salt Lake City, UT 84157-1365.

TRUESCAN is a product of Calera Recognition Systems, 2500 Augustine Drive, Santa Clara, CA 95054.

MS DOS is a product of Microsoft Corporation, 16011 NE 36th Way, Box 97017, Redmond, WA $98073-9717$.

PKZIP is a product of Pkware, Inc., 7545 N. Port Washington Rd., Glendale, WI 53217. 


\section{You are Cordially Invited to Call Us!}

RCEBBS is continually evolving so it may be possible that when you call you will find some slight changes or additions to the features described above. It is our goal to provide the best computer based information service in the state that deals with agriculture and natural resource information.

Your comments and suggestions will be appreciated. 